\title{
Evaluation of Popcorn inbred lines for disease severity
}

\author{
Muhammad Noor ${ }^{1 *}$, Hidayat ur Rahman ${ }^{1}$ and Muhammad Iqbal ${ }^{2}$ \\ 1. Department of Plant Breeding and Genetics, University of Agriculture, Peshawar, Pakistan. \\ 2. Cereal Crops Research Institute, Pirsabak Nowshehra, Khyber Pakhtunkhwa, Pakistan. \\ *Corresponding author's email: noor_pbg49@yahoo.com \\ Citation \\ Muhammad Noor, Hidayat ur Rahman and Muhammad Iqbal. Evaluation of Popcorn inbred lines for disease severity. \\ Pure and Applied Biology. Vol. 4, Issue 3, 2015, pp 288-295. http://dx.doi.org/10.19045/bspab.2015.43002 \\ Received: 19/06/2015 \\ Revised: 24/07/2015 \\ Accepted: $30 / 07 / 2015$
}

\section{Abstract}

In maize crop maydis leaf blight (MLB) is a sever disease in Pakistan like other countries of the world. Twelve $F_{1}$ hybrids were generated in a full diallel mating of four elite popcorn inbred lines. These $\mathrm{F}_{1}$ hybrids along with parents were evaluated at Cereal Crops Research Institute (CCRI), Pirsabak, Nowshera for combining ability of disease severity. Disease data of four inbred lines with their single cross hybrids were analyzed using GGE Biplot. Both general and specific combining ability (GCA and SCA) were found significant for disease severity. Pop-4 was identified as best general combiner for disease severity, while Pop-1 and Pop-2 were having the maximum projection on average tester coordinate (ATC) Y-axis exhibiting the highest SCA effects for disease severity. These promising inbred lines need further evaluation across different productive environments in larger field trials to confirm their heterotic behavior.

Keywords: MLB; Maize; General combining ability; average tester coordinate.

\section{Introduction}

Maize (Zea mays L.) is the most important crop after wheat in Pakistan where it was grown on about 0.51 million hectares with a total production of 0.96 million tons and average yield of 1.88 ton $\mathrm{ha}^{-1}$ in a single province Khyber Pakhtunkhwa (KP) [1]. Maize is the primary crop in majority of the farming systems and also staple food of the rural population and poor resource farmers in KP [2]. Although the average yield of maize has dramatically increased in the last decade in Pakistan, an additional increase in yield will be required to meet future needs of the country. Despite its high yield potential, one of the major limiting factors to maize grain yield is its sensitivity to several diseases $[3,4]$. Approximately 65 pathogens infect maize [5]. Most of the diseases are difficult to control since their occurrence is less predictable year to year because they depend very much on the prevailing weather conditions and are also influenced by the variable production environments [6] and [7]. As a result, in favorable seasons with high rainfall, some diseases also become more prevalent and damaging. Most of small-scale farmers cannot afford, in most cases, to control the diseases through the use of pesticides. Southern corn leaf blight (SLB) or may dis leaf blight (MLB) caused by Helminthosporium maydis is a serious fungal disease of maize throughout the world where maize is grown under warm, humid conditions [8]. Three races of $C$. heterostrophus known as $\mathrm{O}, \mathrm{T}$ and $\mathrm{C}$ have been described $[9,4,10]$. Race $\mathrm{O}$ is considered as the most common race in most 
areas where MLB occurs which infects all types of maize and is controlled by nuclear genes. Race T, the cause of 1970's epidemic in North America is specific to maize containing Texas male-sterile cytoplasm (cms-T) and is controlled mainly by cytoplasmic factors. The most prominent difference between race $\mathrm{O}$ and $\mathrm{T}$ is that race $\mathrm{O}$ only attacks leaves while race $\mathrm{T}$ attacks all plant parts. Race $\mathrm{C}$ is a cms-C cytoplasm-specific race reported only in China. Breeding resistant varieties to maydis leaf blight is the most efficient, economical and sustainable way than chemical control in the long run. Moreover, it also ensures environment safety standards.

Diallel analysis is primary method and has been widely used to determine combining ability, heterotic responses and patterns in maize populations [11, 12]. Combining ability analyses are widely used in maize breeding programs to determine general combining ability (GCA) and specific combing ability (SCA) information of maize germplasm for identification of nature of genes action involved in the expression of quantitative traits, genetic diversity evaluation, suitable parental lines selection for hybridization, heterotic pattern classification, heterosis estimation, and hybrids development [13, 14, 2, 15, 17]. GCA is average performance of a parent in a series of crosses and SCA designates those cases in which certain combinations perform relatively better or worse than would be expected on the basis of average performance of lines involved. The GCA includes additive and additive $\times$ additive variances, while SCA responsible for nonadditive genetic variances.

Biplots can also be used for analyzing diallel crosses [18, 19]. Although the GGE biplot methodology was developed for multienvironment trial (MET) data analysis, but they stated that it also applicable to all types of two-way data that assume an entry-by tester data structure. In MET data, genotypes represent entries and environments are testers. In diallel data, each genotype is both an entry and a tester [19]. The graphical representation in a biplot analysis allowed a rapid and effective overview of GCA and SCA effects of the inbred lines, their performance in crosses, as well as grouping patterns of similar genotypes. The objectives of the present study were to study the combining abilities of 4 maize inbred lines for leaf blight resistance to promote their use by breeders.

\section{Materials and Methods}

Four inbred-lines of popcorn were used in this study. These inbred-lines were crossed following a complete diallel fashion to produce single cross (SC) hybrids during spring season 2012. All the SC hybrids (including reciprocals) were evaluated along with parents in randomized complete block design with three replications in the following summer season (July to October, 2012) at Cereal Crops Research Institute, Nowshehra, Pakistan. Each plot consisted of two rows with 5 meter length and $0.75 \mathrm{~m}$ apart. Two seed per hill were planted which were later thinned to have a population density of 53,333 plants $\mathrm{ha}^{-1}$ at 4-5 leaf stage. Standard cultural practices were applied uniformly at all experimental units. Disease data was recorded on weekly basis in each plot. The plants were visually rated 5 times for percent MLB severity beginning at two weeks post-anthesis [20]. MLB was rated with a 0-5 scale based on leaf's diseased area following [21] procedure, i.e. 0 for no lesion and 5 for heavily blighted leaves. Lines were categorized as 0-1.4 resistant, 1.5-2.4 moderately resistant and 2.5-5.0 susceptible [22]. An arbitrary gradation of 10 classes scale (i.e. $0.5,1.0$, $1.5,2.0,2.5,3.0,3.5,4.0,4.5$ and 5.0) was also used to measure more accurately the disease severity [23]. 


\section{Results and Discussion}

General and specific combining ability

Using GGE Biplot general combining ability (GCA) and specific combining ability (SCA) effects for disease severity of the popcorn inbred lines (entries) were examined by drawing an average tester coordinate (ATC) view for entries. The GCA effect of the entries was approximated by the projection of their markers to the ATC X-axis (the single arrowed line; the direction indicated the positive end) while the SCA of the entries was approximated by the projection of their markers to the ATC Y-axis (double arrowed line) [19]. Significant variation were observed among male parent for disease severity (Table 1). Total variation of $77.5 \%$ (40.4 and $37.1 \%$ by PC1 and PC2, respectively) was explained by Biplot for disease severity (Fig. 1). Our results were in accordance with that of [24] who observed $76.44 \%$ of total variation explained by GGE Biplot for disease severity. As shown in Fig. 1a, Pop-4 has a largest projection onto ATC $\mathrm{X}$-axis exhibiting the highest and positive GCA effect for disease severity. Similarly, Pop-1 also showed higher and positive GCA effects. Whereas, Pop-2 and Pop-5 were located on the left side of the ATC Y-axis (in the opposite direction of ATC X-axis) indicating the lowest and negative GCA effects. The Biplot also displayed the SCA effects of the entries, the vectors length help in ranking the entries as shown in Fig. 1a. Since, the entries Pop-1 and Pop-2 have the largest projections on to the ATC Y-axis exhibiting that they have the highest SCA effects for disease severity. Similarly Pop-4 also showed highest and positive SCA effects. Whereas, entries Pop-5 showed smallest SCA effects (small projections on to ATC Y-axis).

\section{Best double cross hybrid combinations}

The polygon view of biplot (Fig. 1b) showed the interaction and best mating partners among entries and testers as mentioned by $[25,19]$. As mentioned by Yan \& Hunt [19], vertex entries are either the best or the poorest mating partners with some or all of the testers. Vertex entries with largest distances from the origin were more responsive to the change of testers relative to other entries within respective groups. Tester which fall in the same sector share the same best mating partner (i.e. entry at the vertex in that sector) and those fall in different sectors have different best mating partners. The polygon view of biplot showed four sectors with entries Pop-4, Pop-1, Pop5 and Pop- 2 as the vertex entries, and are referred as 1st, 2nd, 3rd and 4th sectors, respectively (Fig 1b). No tester fell in the $3^{\text {rd }}$ and $4^{\text {th }}$ sectors, depicting that the vertex entries (Pop-5 and Pop-2 respectively) of the said sectors were not the best mating partner, with any of the tester, and produced worst combinations. In the 1st sector where Pop-4 is a vertex entry, produced best hybrids with tester POP-1, POP-2 andPOP5 . These combinations Pop $-4 \times$ POP-2, Pop$4 \times \mathrm{POP}-1$ and Pop $-4 \times$ POP-5showed disease highest degree of severity 9.0, 8.4 and 6.8, respectively (Table 2). A single tester POP-4 fell in $2^{\text {nd }}$ sector, meaning that entry Pop-1 (vertex entry) was the best mating partner for POP-4. Based on original data (Table 3). Maximum resistance of 6.3 to was observed for Pop- $2 \times$ POP-4 and Pop-5 $\times$ POP -4 . The possible reason may be that these crosses were apparently inferior to those that were identified to be superior based on Fig 1b. As mentioned earlier that the biplot explained only 77.5 of the total variation rather than $100 \%$, therefore such contradictions are expected to be raised [19]. 
Table 1. Analysis of four maize inbred lines and their crosses

\begin{tabular}{llllll}
\hline SOV & DF & SS & MS & F & P \\
\hline Rep & 2 & 0.107917 & 0.053958 & 0.829242 & 0.45 \\
Female (F) & 3 & 0.720833 & 0.240278 & 1.8185 & 0.21 \\
Male (M) & 3 & 1.609167 & 0.536389 & 4.059566 & 0.04 \\
F $\times$ M & 9 & 1.189167 & 0.13213 & 2.030594 & 0.07 \\
Error & 30 & 1.952083 & 0.065069 & & \\
\hline Total & 47 & 5.579167 & & & \\
\hline
\end{tabular}

Table 2. Biplot axis scores (X-axis and $\mathrm{Y}$-axis) and eigenvectors (PC1 and $\mathrm{PC} 2)$ for the entries and testers.

\begin{tabular}{lllll}
\hline & \multicolumn{2}{c}{ Axis Scores } & \multicolumn{2}{c}{ Eigenvectors } \\
\hline Name & X-axis & Y-axis & PC1 & PC2 \\
\hline Entries & & & & \\
Pop-4 & 0.943 & -0.315 & 0.632 & -0.22 \\
Pop-1 & -0.584 & -1.023 & -0.392 & -0.715 \\
Pop-2 & 0.503 & 0.625 & 0.337 & 0.437 \\
Pop-5 & -0.861 & 0.713 & -0.577 & 0.499 \\
Testers & & & & \\
POP1 & 0.58 & -1.026 & 0.393 & -0.695 \\
POP2 & 1.13 & 0.018 & 0.765 & 0.012 \\
POP4 & -0.466 & -1.052 & -0.316 & -0.713 \\
POP5 & 0.591 & 0.141 & 0.401 & 0.096 \\
\hline
\end{tabular}

Table 3. Mean values of disease severity of single cross progenies (including reciprocals), and self progenies (diagonal) of four popcorn inbred lines.

\begin{tabular}{llllll}
\hline \multicolumn{5}{c}{ Testers } \\
\hline Entries & POP1 & POP2 & POP4 & POP5 & Entries Mean \\
\hline Pop-1 & $\underline{8.0}$ & 7.5 & 7.5 & 6.9 & 7.5 \\
Pop-2 & 6.9 & $\underline{8.3}$ & 6.3 & 7.5 & 7.3 \\
Pop-4 & 8.4 & 9.0 & $\underline{6.4}$ & 6.8 & 7.7 \\
Pop-5 & 6.4 & 7.5 & 6.3 & $\underline{6.5}$ & 6.7 \\
Testers Mean & 7.4 & 8.1 & 6.6 & 6.9 & \\
\hline
\end{tabular}



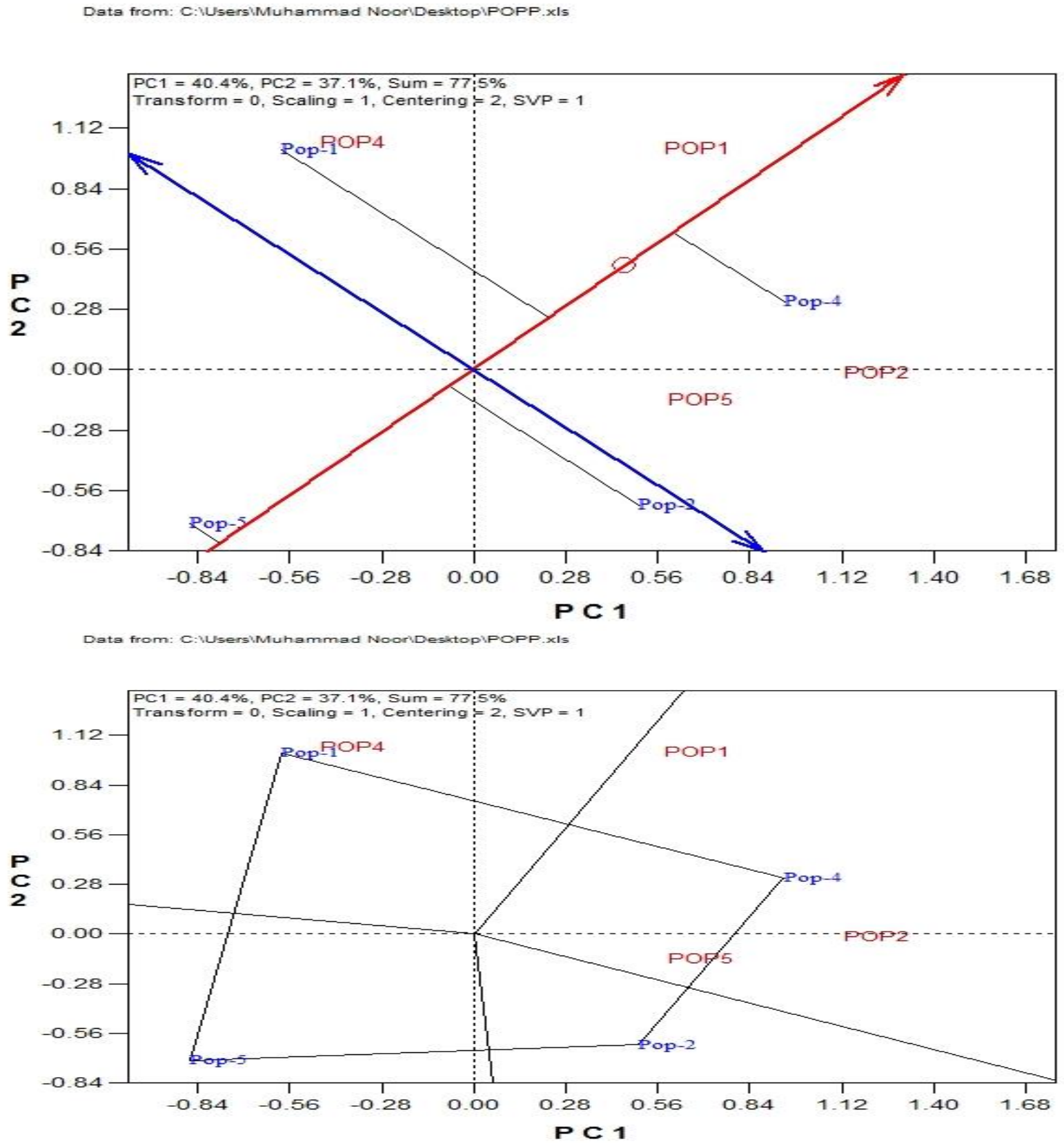

Fig. 1. Biplot based on diallel data of five maize hybrids for grain yield. (A) Average tester ordination view; (B) Polygon view. Codes for genotypes are: POP-1 = ICI-974, POP-2 = Opener, POP-3 = CS-201, POP-4 =CS-222, POP-5 = Pioneer 3025. Genotypes are labeled with uppercase letters when viewed as testers (parents, single crosses) and with lowercase letters when viewed as entries (double crosses) 

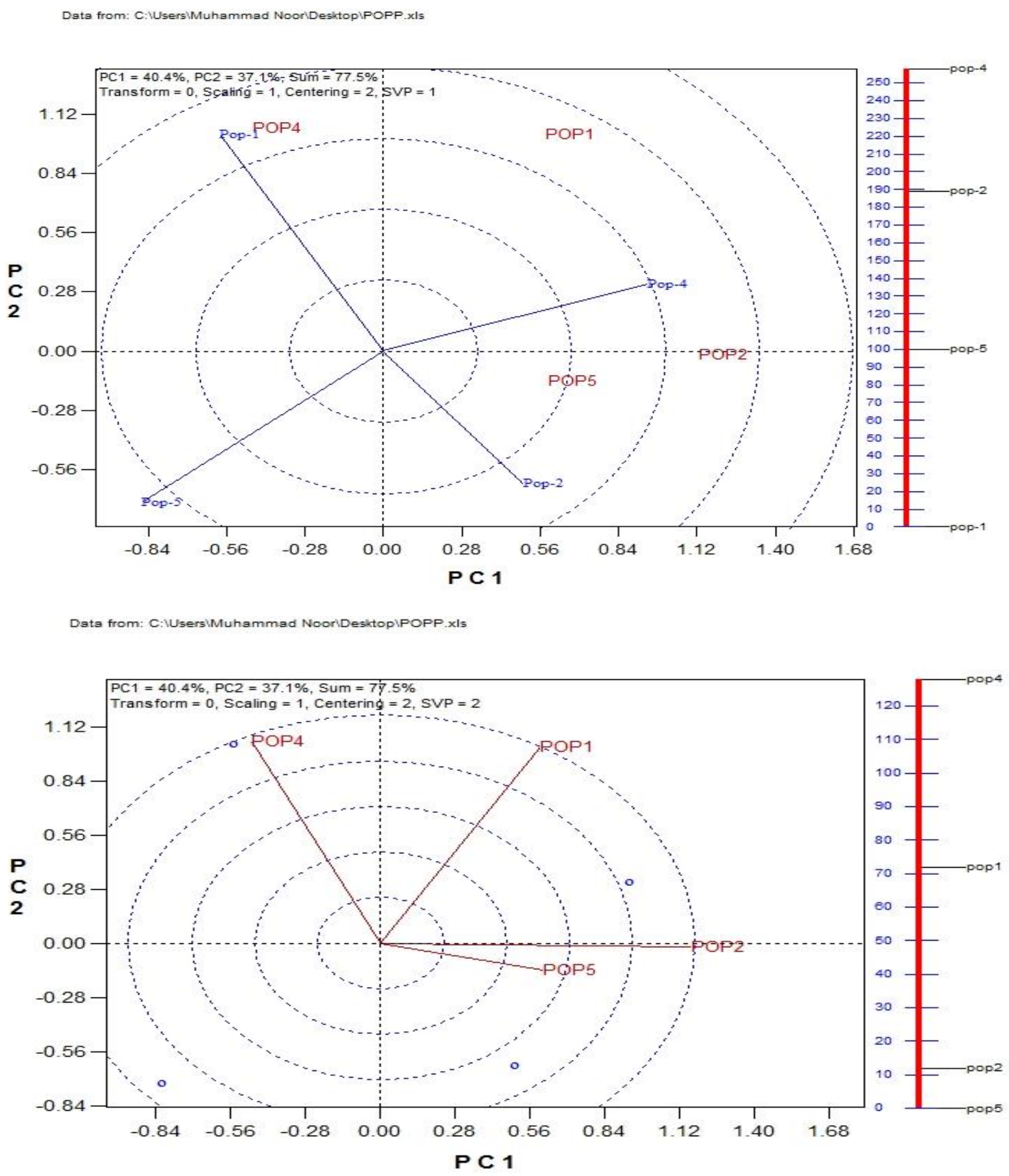

Fig. 2. Biplot showing relationship among genotypes. (A) Relationship among entries (progenies); (B) Relationship among testers (parents). 


\section{Relationship among genotypes}

Biplot provide an attractive and informative view of interrelationship among genotypes (Fig. 2) and (Table 2). The lines that connect the biplot origin and the markers of the genotypes are known as vectors. The angle between vectors of two genotypes relates to the correlation coefficient between them, and the linear map to the right of the graph (in degrees) help in explaining the relationship among them [26, 16]. The genotypes having and acute angle will be positively correlated with each other [19]. Strong positive correlation was observed between entries Pop-2 and Pop-4 (Fig 2a). High positive correlation was observed between testers POP2 and POP5. Tester POP2 showed a negatively correlation (angle $>90^{\circ}$ ) with tester POP4 (Fig. 2b).

\section{Conclusion}

The GGE biplot concise information about general and specific combining abilities. We identified Pop-4 with the highest and positive GCA effect for disease severity followed by Pop-1. On the other hand Pop-2 and Pop-5 showed lowest and negative GCA effects. The SCA effects reported for Pop-1, Pop-2 and Pop-4, indicated the role of dominant gene, which could be utilized in hybrid development based on this trait.

\section{References}

1. Anonymous (2009). Agricultural Statistics of Pakistan. Govt. of Pakistan. Ministry of Food, Agric. \& Livest. Econ. Wing, Islamabad.

2. Khan K, Iqbal M, Shah Z, Ahmad B, Azim A \& Sher H (2003). Grain and stover yield of corn with varying times of plant density reduction. Pak J Biol Sci 6(19): 1641-1643.

3. Shah SS (2006). Recurrent Selection for maydis leaf blight resistance and grain yield improvement in Maize. Ph. D. Dissert. NWFP Agric. Univ. Peshawar, Pakistan.
4. Ali F, Pan Q, Chen G, Zahid KR \& Yan JB. 2013. Evidence of multiple disease resistance (MDR) and implication of meta-analysis in marker assisted selection. PloS One 8(7): e68150.

5. Rahul K \& Singh IS (2002). Inheritance of resistance to banded leaf and sheath blight (Rhizoctonia solam f. sp. Sasakii) of maize. 8th Asian Regional Maize Works. Bangkok, Thailand 5-8: 356-365.

6. Ali, F, Yan JB (2012). Disease resistance and role of molecular breeding in defending against global threat. $J$ integrative Plant Biol

7. Vivek BS, Odongo O, Njuguna J, Imanywoha J, Bigirwa G, Diallo A\& Pixley K (2010). Diallel analysis of grain yield and resistance to seven diseases of 12 African maize (Zea mays L.) inbred lines. Euphytica 172: 329-340.

8. White DG (1999). Compendium of Corn Diseases. 3rd ed. The Amer. Phytopath. Soci. St. Paul, MN.

9. Smith DR, Hooker AL \& Lim SM (1970). Physiologic races of Helminthosporium maydis. Plant Dis Rep 54: 819-822.

10. Wei J, Lui K, Chen J, Luo P \& LeeStadelmann OY (1988). Pathological and Physiological identification of race $\mathrm{C}$ of Bipolaris maydis in China. Phytopathalogy 78: 550-554.

11. Bertoia L, Lopez C \& Burak R (2006). Biplot analysis of forage combining ability in maize landraces. Crop Sci 46: 1346-1353.

12. Hallauer HA \& Filho MJB (1981). Quantitative genetics in maize breeding. Iowa State Univ. Press, Ames, IA.

13. Barata C \& Carena M (2006). Classification of North Dakota maize inbred lines into heterotic groups based on molecular and testcross data. Euphytica 151: 339-349.

14. Falconer DS (1979). Introduction to quantitative genetics, 3rd edition, Longman grp. Essex. 
15. Ali F, Shah IA, Rahman H, Noor M, Durrishawar, Khan MY, Ullah I, Yan JB \& Shaukat S. 2012. Heterosis for yield and agronomic attributes in diverse maize germplasm. Aus J Crop Sci 6(3): 455462.

16. Fan XM, Chen HM, Tan J, Xu CX, Zhang YD, Luo LM, Huang YX \& Kang MS (2008). Combining abilities for yield and yield components in maize. Maydica 53: 39-46.

17. Melani MD\& Carena MJ (2005). Alternative maize heterotic pattern for the Northern Corn Belt. Crop Sci 45: 21862194.

18. Bhatnagar S, Betran FJ\& Rooney LW (2004). Combining ability of quality protein maize inbreds. Crop Sci 44: 1997-2005.

19. Yan W \& Hunt LA (2002). Biplot analysis of diallel data. Crop Sci 42: 2130.

20. Carson ML, Stuber CW\& Senior ML (2004). Identification and mapping of quantitative trait loci conditioning resistance to southern leaf blight of maize caused by Cochliobolus herterostrophus race O. Phytopathology 94: 862-867.
21. CIMMYT (1985). Managing trails and reporting data for CIMMYT's International Maize Testing Program. CIMMYT, El Batan, Mexico.

22. Muriithi LM\&Mutinda CJM (2001). Genetic Variability of maize genotypes for resistance to Exserohilum turcicum in Kenya. Eastern and Southern African Regional Maize Conf., 106-109.

23. Jenkins MT \& Robert AL (1961). Further Genetic studies of resistance to Helminthosporium turcicum in maize by means of chromosomal translocations. Crop Sci 1: 450-455.

24. Sibiya J, Tongoona P \& Derera J (2013). Combining ability and GGE biplot analyses for resistance to northern leaf blight in tropical and subtropical elite maize inbred lines. Euphytica 191:245257.

25. Yan W, Hunt LA, Sheng QW \& Szlavnics Z (2000). Cultivar evaluation and mega-environment investigation based on the GGE biplot. Crop Sci 40: 597-605.

26. Yan W \& Kang MS (2003). GGE Biplot Analysis: A graphical tool for breeders, geneticists, and agronomists. CRC Press, Boca Raton, FL. 